\title{
Understanding the Barriers to Introducing Early Palliative Care for Patients with Advanced Cancer: A Qualitative Study
}

\author{
Aline Sarradon-Eck, MD, PhD, ${ }^{1,2}$ Sylvain Besle, $\mathrm{PhD}^{1,3}$ Jaïs Troian, $\mathrm{MSc}^{4}$ \\ Géraldine Capodano, MD, and Julien Mancini, MD, $\mathrm{PhD}^{6}$
}

\begin{abstract}
Background: Palliative care is often underutilized or initiated late in the course of life-threatening illness. Randomized clinical Early Palliative Care (EPC) trials provide an opportunity for changing oncologists' perceptions of palliative care and their attitudes to referring patients to palliative care services.

Aim: To describe French oncologists' perceptions of EPC and their effects on referral practices before a clinical EPC trial was launched.

Design: A qualitative study involving semistructured face-to-face interviews. The data were analyzed using the Grounded Theory coding method.

Setting/Participants: Thirteen oncologists and 19 palliative care specialists (PCSs) working at 10 hospitals all over France were interviewed. Most of them were involved in clinical EPC trials.

Results: The findings suggest that referral to PCSs shortly after the diagnosis of advanced cancer increases the terminological barriers, induces avoidance patterns, and makes early disclosure of poor prognosis harder for oncologists. This situation is attributable to the widespread idea that palliative care means terminal care. In addition, the fact that the EPC concept is poorly understood increases the confusion between EPC and supportive care.

Conclusion: Defining the EPC concept more clearly and explaining to health professionals and patients what EPC consists of and what role it is intended to play, and the potential benefits of palliative care services could help to overcome the wording barriers rooted in the traditional picture of palliative care. In addition, training French oncologists how to disclose "bad news" could help them cope with the emotional issues involved in referring patients to specialized palliative care.
\end{abstract}

Keywords: cancer; early palliative care; France; medical culture; qualitative study; social representation

\section{Introduction}

D ESPITE THE EVIDENCE of its benefits, palliative care has been reported to be often underutilized or initiated late in the course of life-threatening illness such as cancer in many countries. ${ }^{1-7}$ Recent literature reviews have shown the existence of several barriers to patients' access to palliative care. ${ }^{8-10}$ The institutional barriers identified include lack of communication between health care teams ${ }^{11,12}$; lack of knowledge and education about palliative care practices and referral policies ${ }^{10-17}$ (in particular, understanding specialized palliative care as a sequential model of care $)^{18}$; low availability of specialized palliative care ${ }^{3,12,17,19}$; oncologists' lack of confidence in their ability to manage patients' symptoms ${ }^{20,21}$; and poor conditions of reimbursement, heavy financial constraints, and low institutional resources. ${ }^{19,22,23}$

A large number of authors have suggested the existence of communication barriers. Surveys have highlighted

\footnotetext{
${ }^{1}$ Aix Marseille University, INSERM, IRD, SESSTIM, Economics and Social Science Applied to Health \& Analysis of Medical Information, Marseille, France.

${ }^{2}$ Institut Paoli-Calmettes, Cancer, Biomedicine \& Society, Marseille, France.

${ }^{3}$ Drug Development Department (DITEP), Gustave Roussy, University Paris-Sud, University Paris-Saclay, Villejuif, France.

${ }_{5}^{4}$ Aix-Marseille University, Psychologie, Marseille, France.

${ }^{5}$ Institut Paoli-Calmettes, Département de Soins de Support et Palliatifs, Marseille, France.

${ }^{6}$ Aix-Marseille University, APHM, INSERM, IRD, SESSTIM, Economics and Social Science Applied to Health and Analysis of Medical Information, Hop Timone, BioSTIC, Biostatistique et Technologies de l'Information et de la Communication, Marseille, France.

Accepted June 22, 2018.
} 
physicians' difficulties in disclosing poor prognosis or discussing terminal illness because of various factors ${ }^{24}$ : oncologists have too little time during their consultations ${ }^{25}$; the uncertainty about cancer care ${ }^{26-28}$; physicians' avoidance of prognosis $^{29}$ and their fear that disclosing the prognosis might be damaging to patients (feelings of abandonment, ${ }^{30,31}$ distress, and the destruction of hope $)^{12,28,32-36}$; and the emotional challenges and issues involved in discussing death and dying, ${ }^{13,24,28,35,37,38}$ especially in the case of young patients ${ }^{13,26,27}$ for psychological and ethical reasons (identification and emotional entanglement, respect for the patients' preferences, and fighting to give them a fair life span). ${ }^{26}$ Several studies have also identified patient- and familyrelated barriers: reluctance to accept referral ${ }^{14,17,19}$ due to patient/family misinformation ${ }^{39,40}$ or the idea that palliative care is equivalent to terminal care. ${ }^{8,18,40-42}$ Physicians therefore fear that referral to palliative care may alarm patients and their families. ${ }^{6}$ However, this idea is also commonly held by health professionals, and prevents them from practicing early referral. ${ }^{3,13,17,18,35,43-45}$ Several authors have stressed the persistence of some terminological confusion about palliative care. ${ }^{3,10,43}$ One systematic review has shown the lack of clear-cut definitions for many important terms in the supportive and palliative oncology literature. ${ }^{46}$

Early Palliative Care (EPC) is a new paradigm ${ }^{47}$ that could overcome the barriers to broader access to palliative care for patients with progressive and incurable cancer. The concept of EPC has been defined as the integration of specialized multiprofessional palliative care into oncological care shortly after the diagnosis of advanced cancer. ${ }^{48}$ Several EPC models have been developed during the last two decades, and randomized clinical trials have shown their benefits to patients with advanced cancer. ${ }^{49-56}$ In this article, the term palliative care is taken to correspond to the holistic approach described by Temel et al., ${ }^{50}$ including management of the physical symptoms, providing psychosocial support, and clarifying patients' understanding of their prognosis and establishing their end-of-life preferences. ${ }^{57-59}$

The sequential care model or "congress practice model" 8 in which palliative care involves only addressing endof-life issues seems to be the main care model adopted at French Cancer Centers, depending on the center and the oncologist responsible for managing patients' cancer care. ${ }^{7}$ One study conducted at several French university hospitals has shown that the great majority of patients with cancer are referred to palliative care too late: the median survival time was only 22 days after the first evaluation by a Palliative Care Consultation Team (PCCT), which was mainly conducted during their last hospital stay. ${ }^{7}$ However, the early introduction of palliative care into the medical management of patients with a progressive incurable disease has been recommended in France since 2002 by the National Health Agency. ${ }^{60}$

Cancer care and palliative care are entirely covered by the French public health insurance system. Despite the existence of geographical disparities, palliative care resources have been increased in France since the Law 99-477 was passed in June 9, 1999, declaring the right to proper access to palliative care and supportive care for all patients. According to the latest data, France (67 million inhabitants) has 157 Acute Palliative Care Units (APCUs), 5057 dedicated palliative care beds (distributed among 835 institutions), 107 palliative care networks (ensuring continuity between the hospital and home care provided by primary care professionals), and 428 PCCTs. ${ }^{61}$ All French Comprehensive Cancer Centers (CCCs) and University Hospitals have one PCCT as well as dedicated palliative care beds. In addition, some of them have proper APCUs. PCCTs are mobile multidisciplinary teams that include Palliative Care Specialists (PCSs) and nurses, with additional support from psychologists, social workers, physiotherapists, and dieticians.

In France, the first PCCT was created in 1989, shortly after the opening of the first inpatient Palliative Care Unit. ${ }^{7}$ The aim of PCCTs is to support hospitals and home care teams and to disseminate information about the palliative culture. PCCTs have a consulting role and advise specialist units only at their request. Oncologists therefore have a critical role to play in deciding whether there is a need for referral to a PCS and how this procedure should be timed.

To implement EPC at French hospitals and promote the "integrated care model", that is, providing palliative care as part of oncological care, ${ }^{8}$ the EPIC trial—a randomized multicenter clinical trial (NCT02853474) —was launched in France in 2017. The objective was to estimate the benefits of EPC in patients with metastatic upper gastrointestinal cancer to determine whether the findings obtained in France are consistent with those obtained in North American trials.

The EPIC trial provides an opportunity for changing French patients' and physicians' perceptions of palliative care. The aim of this qualitative study was therefore to investigate these perceptions and their effects on physicians' referral practices. A sociological approach was used in this study to unravel the social and cultural factors underlying oncologists' attitudes to early referral to palliative care services and working together with PCSs in French hospital settings.

\section{Methods \\ Design}

This qualitative study, which was conducted from October 2015 to May 2017 before the EPIC trial was launched, involved semistructured face-to-face interviews with oncologists and PCSs.

Ethical approval was obtained from the French Institute of Medical and Health's Research Ethics Committee (IORG0003254 and FWA00005831) and Institutional Review Board (IRB00003888) (Opinion number 15-264). All participants gave their consent after receiving both oral and written information about the study.

\section{Sample}

Thirteen oncologists and nineteen PCSs (16 MDs and 3 resident physicians) were interviewed, based on a purposive sampling strategy. The oncologists $(n=13)$ and most of the PCSs $(n=11)$ working at four of the CCCs involved in the EPIC trial were interviewed. To obtain various viewpoints about referral to PCSs, interviews were also conducted with five PCSs working at three other CCCs and University hospitals involved in the EPIC trial and three PCSs working at University hospitals not involved. The oncologists and PCSs interviewed were at different stages in their career trajectory (Table 1). 
Table 1. Physicians' Characteristics

\begin{tabular}{lcc}
\hline Characteristics & $\begin{array}{c}\text { Oncologists } \\
(\mathrm{n}=13)\end{array}$ & $\begin{array}{c}P C S s \\
(\mathrm{n}=19)\end{array}$ \\
\hline $\begin{array}{l}\text { Age (years) } \\
\quad 40\end{array}$ & 5 & 6 \\
$\quad 40-50$ & 7 & 5 \\
$>50$ & 1 & 8 \\
Gender & & \\
$\quad$ Male & 8 & 8 \\
$\quad$ Female & 5 & 11 \\
Hospital setting & & \\
$\quad$ University Hospital & 0 & 4 \\
$\quad$ Involved in the EPC trial & & 1 \\
$\quad$ Not involved in the EPC trial & & 3 \\
$\quad$ Comprehensive Cancer Center & 13 & 15 \\
$\quad$ involved in the EPC trial & & \\
\hline
\end{tabular}

EPC, Early Palliative Care; PCS, palliative care specialists.

\section{Procedure}

The principal investigator (A.S.-E.), a medical anthropologist, who was not working with the participants and did not have any clinical activities in the oncology wards involved, approached the participants by e-mail and conducted the interviews at physicians' offices The interviews were carried out individually to prevent any influence or bias due to the presence of other participants.

The semistructured interview guide used covered the following areas: physicians' perceptions of palliative care, communicating prognoses, current referral practices, perceived barriers to patients' access to EPC, and physicians' opinions about the EPIC trial (see Appendix A1). Interviews were audio-recorded and transcribed. All personally identifiable information was removed from the transcripts.

\section{Data analysis}

The first author conducted a qualitative analysis of each interview manually, using the Grounded Theory coding method. ${ }^{62}$ Units of meaning were words, sentences, and parts of sentences. Interviews were coded using an inductive iterative process. Segments of interviews were sorted into categories until the categories accounted for all the variations in the data. Codes were refined and reformulated by gradually incorporating more interviews into the coding structure. Selective coding and relationships between the categories were refined and core categories were identified and arranged into broad emergent thematic groups. In this study, we focus on two thematic groups alone: perception of palliative care and participants' misunderstandings about the EPC concept.

To assure the robustness of the analysis, the following strategies were used: saturation, reflexivity, and a peer review. Data collection and analysis were conducted simultaneously and until no further news items emerged (theoretical saturation was reached). The data codes, categories, and themes were constantly checked, compared, and contrasted. Core categories and themes were discussed at interdisciplinary team meetings (including a sociologist, a sociopsychologist, a PCS, and a Public Health researcher) and examined in relation to the existing literature to spot any inaccuracies and misinterpretations. Preliminary results were presented at two research conferences (the EAPC 2017 World Congress and the SFAP 2018 Congress) to obtain feedback from peers, which was positive.

\section{Results}

\section{How physicians' perception of patients' understanding of palliative care affects their referral practices}

Both oncologists and PCSs stated that palliative care is thought by patients and their families to mean imminent death, hospice care, and end-of-life care. These results show how physicians' perception of patients' understanding of palliative care impacts the process of communication and patients' referral to palliative care services.

Effects on physicians' discourse: avoidance of the word "palliative care". The word "palliative" was said to hold negative connotations for patients, which make it difficult for oncologists to use it when talking to them. Most of the oncologists interviewed mentioned that this word is "unsuitable", that it "scares people" and "harms them" even, because it suggests that patients will stop being treated or be abandoned, or even have to undergo heavy sedation or euthanasia.

The patients get the feeling that we are going to stop trying, shut the door on them, and wait for the end (P6, an oncologist).

The respondents said that this failure to understand what EPC involves is an obstacle to its acceptance by patients and families.

The oncologists and some of the PCSs interviewed said using the word palliative with patients not in the terminal phase of the disease constitutes a form of "violence". To overcome this problem, they adopted various semantic strategies based on the use of euphemisms (such as "comfort care", "supportive care", "pain relief", "a whole approach") to introduce palliative care more "gently"; defining what palliative care is all about, often by explaining the etymological roots of the word; and praising PCSs' model for care and explaining the underlying philosophy:

It's true that we rarely pronounce the words "palliative care" straight away. We generally begin by talking about comfort care, support, whole treatment, and alleviating pain, and tell them about the physicians in the establishment who are specialized in support of this kind (...). Sometimes we even exaggerate a bit by saying you will be better there than here because the treatment focuses on the patients' comfort and on listening to what they have to say, whereas we are always in a hurry here, dispensing the treatment, and we sometimes overlook some things and don't take the time... (P17, an oncologist).

All the oncologists interviewed said they would be more likely to refer patients for palliative care at an earlier stage if it was renamed "supportive care". Most of them stated that they would not present the EPIC trial to eligible patients as a "palliative care" investigation, but rather as a "supportive care" investigation. 
Making a change of name. Some of the PCSs interviewed said they had renamed their department "Supportive Care Unit" because of the stigmatization of palliative care.

Professionals used to have-or still have-very negative representations. In other words, they picture palliative care like waiting in the death row. That's why I changed the name of the department. (P12, a PCS).

However, PCSs do not all want to give up the term "palliative care." First, because of its special significance in terms of the principles and practices to which they are attached, especially in their fight against society's denial of death.

We have thought about changing our name but (...) the fact that it's difficult to talk about palliative care and palliative medicine also reflects the inclination to shy away from death, which is actually one of the reasons for which we are doing our work (P18, a PCS).

Wrapping things up in pink tissue paper with a pretty ribbon is not doing people a service (...). In the society we live in, death, illness, and old age tend to be pushed aside. I don't really think that changing the name to find something more widely acceptable would be doing people a service (P5, a PCS).

Second, because some PCSs said they wanted to differentiate palliative care from supportive care. They objected that the supportive care practices adopted at some hospitals focus on one particular symptom, which amounts to disintegrating the patients in a way that runs contrary to the allinclusive principles of palliative care.

However, some other PCSs pointed out that once palliative care has been introduced at an earlier stage in advanced cancer patients' care trajectory, it tends to become more technical and invasive than in the original approach to palliative care, when the main idea was to assist end-of-life patients. This contributes to blurring the boundaries between palliative care and supportive care.

Effects on referral practices. Because of the patients' perception of PC as end-of-life care, the oncologists interviewed feared that announcing referral to a PCS might have negative effects on patients by causing a loss of compliance with their palliative chemotherapy or a loss of hope and feelings of distress. According to the respondents, that is why some oncologists are reluctant to refer patients for EPC:

The Head of a thoracic oncotherapy ward just told me, "If I inform people that they have small cell cancer or metastases, and then go on to say I am going to call in the mobile palliative care team, they are going to throw themselves under a train!" (P12, a PCS).

In the physicians' discourse, referral to a PCS appears to be equivalent to announcing a poor prognosis:

EPC means referring patients at an early stage in their disease. But we are already trying to tell them they have cancer, and I feel it's a bit much to have to also say, "We are going to transfer you to palliative care because there is nothing else we can do" because palliative care has strong connotations. And while I am saying that, I realize that since we are talking about a serious disease, we should really go on to mention the prognosis straight away... but to me, that seems to be a difficult thing to do ... Announcing at a single con- sultation "you have cancer, and the cancer is at a very advanced stage"... amounts to announcing a lot of things all at the same time ( $\mathrm{P} 4$, an oncologist)

This situation may be a barrier to patients' access to EPC, even in the context of the EPIC trial, not only because it is distressing and painful for both patients and oncologists but also because announcing a short lifetime scenario also seems to run counter to the medical culture focusing on curing patients, especially at CCCs (which are called "Cancer-fighting Centres"' in France):

The EPIC trial won't suit everybody. I expect telling some patients about palliative care right at the start would make them run away...There are some people who have not come all the way to this center to be told...it's the end, you can have palliative care... They come here in the hope of being cured. It's bad enough having to tell them that no cure exists without adding that they can have palliative care, it's not always easy for them to take it in...they sometimes come with inordinately high hopes. The CCCs raise the hopes of the people attending them. When they have come a long way, their expectations are even higher (P22, an oncologist).

The oncologists interviewed admitted that they had not been trained to deliver bad news, apart from their on-the-job training. Some of them had nevertheless developed special strategies: they informed patients "gradually" during several consultations, but recognized the existence of a risk that this might delay patients' referral to a PCS.

\section{EPC: a poorly understood concept}

Some of the oncologists interviewed said that palliative care should be kept for patients whose life expectancy amounted to less than three months. This long-established picture of palliative care causes some confusion about the meaning of "palliative" cancer treatment and explains why some physicians are reluctant to resuscitate patients undergoing palliative chemotherapy.

If you write "palliative chemo", they [the intensive care staff] will say "but if it's palliative chemo, what's the point of treatment? It's the end, he's had a huge infection, a pulmonary edema or some kind of complication or a severe embolism or whatever, let him go and that's that." Whereas if you treat whatever it is, the patient is going to live for another few months or years. Whenever the word palliative is written down, you have to negotiate with people every time. (P10, an oncologist).

In many oncologists' practices, palliative care is the last resource, when there exists no other possible treatment. Some of the oncologists interviewed defined palliative care negatively, that is, by what it is not.

I refer patients for palliative care when there exists no other possible treatment ...I use the term palliative care when there are no other kinds of chemotherapy left to try... when the patient's general physical condition is very poor (P16, an oncologist).

Some PCSs thought the value of palliative care is not properly recognized:

They (the oncologists) accept us ...they feel it's useful but they don't think it's proper medicine. Proper medicine is cancerology, the medicine which treats people... When we 
have no choice, we turn to palliative care but...it's not in the same league (P23, a PCS).

In view of the above statements, one can say that PCSs are regarded as service providers rather than delivering care as part of integrated care projects:

We have to serve some purpose, in other words, they use us because we help to solve their problems, but (...) they do not regard us as being an integral part of integrated care (...) We help them to get over a difficult patch or to sort out tricky situations...(...) but as long as this is not an obligatory procedure, our role is difficult to...I mean we are still working in parallel, as stand-bys (P19, a PCS).

Finally, some of the oncologists interviewed depreciated palliative care practices, describing them as not always evidence-based practices. They objected that palliative care is not properly defined or only "in very vague terms", "not terribly exactly": "I have never been able to understand what this so-called whole person care means". Others mentioned criticisms made by colleagues: that palliative care is "just hot air" and consists of "holding patients' hands until they die".

Some of the oncologists interviewed stated that EPC is the same thing as supportive care. From their point of view, oncologists are specialized in treating cancer and PCSs in treating symptoms. That is why they found it difficult to refer asymptomatic patients to a PCS at an early stage.

This division of medical labor into subspecialties does not necessarily mean that there exists a barrier between the two. Rather, it could lead to the two professional segments working together to improve patients' care:

\begin{abstract}
We hand over very readily to the PCSs because they have greater competence and experience and...on the other hand, this makes it possible to separate the treatment of pain from the cancer treatment (...). At private clinics, where there is no such assistance at all, the oncologists are all alone with their patients and have to manage their pain, their end of life and their cancer, and... there is bound to be a moment when... one is less proficient when one is working alone (P22, an oncologist).
\end{abstract}

The latter excerpt highlights the fact that in France, medical oncologists often have to provide both supportive and palliative care, either because they are working at private clinics with no PCSs or because some of them (especially the oldest ones) feel they are responsible for providing cancer patients with all the care they need, including their end-of-life care. PCSs find it difficult to work together with these practitioners, especially since the specialization of PCSs is not unanimously recognized at French hospitals:

It's funny because when doctors ask a cardiologist for his opinion, he will say "do this and do that": nobody will question his advice (...) and his prescriptions will be applied. But when patients need palliative care, especially end-of-life care, everybody thinks they have been properly trained for this. They tell themselves "anyone can handle the end of life, anyone can handle pain" (...). And we often get the impression that they think our intervention means they lack ability (...) We can provide expertise which can be helpful or even sometimes support the medical teams, but this assistance is underestimated and it is not yet recognized as a specialty (P20, a PCS).
This lack of legitimacy can generate conflicts over professional boundaries, which block recourse to EPC.

\section{Discussion}

These findings bring to light the fact that referral to PCS early after the diagnosis of advanced cancer increases the terminological barriers, induces avoidance patterns, and makes early disclosure of poor prognosis harder for oncologists. The main reason for this situation is the restrictive picture of palliative care as terminal care. In addition, the generally poor understanding of the EPC concept increases the confusion between EPC and supportive care. The sociological approach adopted in this study helps to explain these findings.

In France, the idea that palliative care is equivalent to endof-life care is rooted in the palliative care movement, which originated in many Western countries in the Hospice movement. The recurrent public debates on the issue of physicianassisted suicide (which is prohibited under French legislation), which have accompanied successive revisions of the French Bioethics Law during the last few decades, have strengthened the tendency to associate palliative care with death because opponents of assisted suicide have been upholding the palliative care model for "the good death", in addition to the philosophical and religious arguments put forward by other people. Palliative care and euthanasia are closely associated in French physicians' minds. ${ }^{63}$ Movements favoring palliative care or euthanasia have contributed to keeping the question of death and dying firmly implanted on the French social scene ${ }^{64}$ and upholding social representations of palliative care as being equated with end-of-life care. The first definition of palliative care, which was put forward by Thérèse Vanier ("When there is nothing more that can be done, everything can still be done"), is still being frequently quoted in French palliative care training courses and handbooks. Although this definition was intended to save end-of-life patients from being abandoned, it reinforces the idea that palliative care is last-resort care, and made it difficult for some of the oncologists interviewed to regard it as being complementary to active cancer care. ${ }^{18}$

These findings confirm that referral to PCS is thought to be equivalent to announcing poor prognoses and low survival rates. Since palliative care was first introduced, the word palliative has always been (over)loaded with meaning. The performative power of the word affects doctors' communication with patients, so that their "belief in the selffulfilling prophecy" leads doctors to avoid prognosticating. ${ }^{29}$

French oncologists, like many of their colleagues around the world, ${ }^{24,36,38}$ fear that disclosing the prognosis may harm their patients. Their desire to protect the patients makes them reluctant to disclose the prognosis shortly after the diagnosis of advanced cancer, and this can even lead to lying strategies, as suggested by Fainzang in his survey on French hospital settings. ${ }^{65}$

However, we do not have sufficient evidence that telling the truth is liable to destroy patients' hope and make them depressed. $^{36,38}$ The existence of links between accurate prognostic understanding and between the acknowledgment of terminal illness and worse psychological distress has been established, but the authors of the latter studies concluded that there is a need to provide appropriate support for patients 
such as those included in EPC programs. ${ }^{66}$ Some studies have suggested, on the contrary, that patients can discuss the topic of their prognosis without undergoing negative effects, ${ }^{24}$ that hope is maintained when patients with advanced cancer are given truthful prognoses, ${ }^{32,67}$ and that prognostic discussions are not necessarily detrimental to the patient-physician relationship and can even strengthen the therapeutic alliance between patients and oncologists. ${ }^{68}$ Ultimately, as Fallowfield et al. have suggested, "reluctance to give bad and sad news probably reflects the difficulty that the doctor experiences in conveying this type of information as much as a desire to protect patients from the distress such knowledge provokes.",38

That is why all the oncologists interviewed said that they would be more likely to refer patients for palliative care if it was renamed supportive care, in line with previous findings. $^{3,43,44}$ This avoidance pattern is based on their belief that making a change of name would allow them to introduce early supportive measures that are complementary to active tumor treatment without the emotional burden of delivering poor prognosis. However this finding also reflects the misunderstanding of the EPC concept and the confusion between palliative care and supportive care. Oncologists' picture of PCSs' work is often restricted to managing the physical symptoms and providing psychosocial support. This picture masks one of the essential components of palliative care, which consists of preparing patients for what lies ahead to give them as much autonomy as possible. ${ }^{57}$

In addition, making a change of name would challenge PCSs' professional identity and the principles of palliative care, and weaken the institutional legitimacy of this emerging medical specialty, which sometimes faces resistance in France from the practitioners of more long-established medical specialties because all the specialties have to compete for legitimacy and resources. ${ }^{63}$

Strategies other than labeling palliative services with a new name should therefore be envisaged. Instead of relying on avoidance patterns, health professionals and patients should be properly informed what palliative care involves, the role it is intended to play and the potential benefits of these services. ${ }^{43,69,70}$ Studies have shown that palliative care education has significantly improved patient care. ${ }^{10}$ The palliative approach needs to be defined more clearly in an integrated care perspective ${ }^{46}$ to facilitate the implementation of EPC programs. In addition, training oncologists to explain what palliative care means would alleviate the burden of announcing poor prognosis and referral to PCSs, ${ }^{36,71}$ and compensate for their lack of training in the disclosure of bad news. Communication strategies preventing patients' feelings of abandonment could be learned. ${ }^{72}$ A German randomized controlled trial has shown that a specific training program can improve oncologists' palliative care communication skills in consultations focusing on the transition to palliative care. ${ }^{73}$

This study has some strengths and limitations. Although the qualitative method used in this study does not make it possible to generalize our findings, the results obtained using a sociological analysis clearly show how tightly imbricated the social and cultural factors underlying these medical practices are. We did not interview oncologists who were totally opposed to referring their patients to PCSs. This does not detract from the validity of our results. On the contrary, the fact that most of the oncologists interviewed were willing to work with PCSs supports our finding that oncologists often regard palliative care as end-of-life care rather than being a fully fledged complementary approach to active care for patients with advanced cancer.

\section{Conclusion}

Several measures need to be envisaged to facilitate the implementation of EPC programs and increase the visibility of palliative care in the French health care system. Defining EPC concepts more clearly and running public education campaigns on what palliative care is all about could help to overcome the terminological barriers resulting from the traditional image of palliative care. In addition, training French oncologists in the disclosure of "bad news" could help them cope with the emotional issues associated with referring patients to specialized palliative care.

\section{Acknowledgments}

The authors would like to thank all the professionals who agreed to participate in this study. They would also like to thank Dr. Jessica Blanc for translating the original version of this article into English. This work was supported by The SIRIC (a comprehensive cancer research group) in Marseille (call for projects 2015), and by IReSP (Research Institute in Public Health) on the occasion of the call for projects "Recherche sur les services de santé et cancer," which was launched in 2015 as part of the cancer plan 2014-2019. None of these funders played any role in the study design, collection, analysis or interpretation of data, or in the drafting of this article.

Prior abstract presentation: "Understanding the barriers to introducing Early Palliative Care for cancer patients in France"' (oral presentation), EAPC 2017, 18-20 May 2017, Madrid, Spain.

\section{Author Disclosure Statement}

No competing financial interests exist.

\section{References}

1. Cheng W-W, Willey J, Palmer JL, et al.: Interval between palliative care referral and death among patients treated at a comprehensive cancer center. J Palliat Med 2005;8:10251032.

2. Osta BE, Palmer JL, Paraskevopoulos T, et al.: Interval between first palliative care consult and death in patients diagnosed with advanced cancer at a comprehensive cancer center. J Palliat Med 2008;11:51-57.

3. Wentlandt K, Krzyzanowska MK, Swami N, et al.: Referral practices of oncologists to specialized palliative care. J Clin Oncol 2012;30:4380-4386.

4. Assi T, El Rassy E, Ibrahim T, et al.: The role of palliative care in the last month of life in elderly cancer patients. Support Care Cancer 2017;25:599-605.

5. Breuer B, Fleishman SB, Cruciani RA, et al.: Medical oncologists' attitudes and practice in cancer pain management: A national survey. J Clin Oncol 2011;29:4769-4775.

6. Smith CB, Nelson JE, Berman AR, et al.: Lung cancer physicians' referral practices for palliative care consultation. Ann Oncol 2012;23:382-387. 
7. Vinant $P$, Joffin I, Serresse L, et al.: Integration and activity of hospital-based palliative care consultation teams: The INSIGHT multicentric cohort study. BMC Palliat Care 2017; $16: 36$.

8. Bruera E, Hui D: Integrating supportive and palliative care in the trajectory of cancer: Establishing goals and models of care. J Clin Oncol 2010;28:4013-4017.

9. Ahmed N, Bestall JE, Ahmedzai SH, et al.: Systematic review of the problems and issues of accessing specialist palliative care by patients, carers and health and social care professionals. Palliat Med 2004;18:525-542.

10. Roenn JHV, Voltz R, Serrie A: Barriers and approaches to the successful integration of palliative care and oncology practice. J Natl Compr Canc Netw 2013;11:S11-S16.

11. den Herder-van der Eerden M, Ewert B, Hodiamont F, et al.: Towards accessible integrated palliative care: Perspectives of leaders from seven European countries on facilitators, barriers and recommendations for improvement. J Integr Care (Brighton) 2017;25:222-232.

12. Le BHC, Mileshkin L, Doan K, et al:: Acceptability of early integration of palliative care in patients with incurable lung cancer. J Palliat Med 2014;17:553-558.

13. Granek L, Krzyzanowska MK, Tozer R, et al.: Oncologists' strategies and barriers to effective communication about the end of life. J Oncol Pract 2013;9:e129-e135.

14. Ward AM, Agar M, Koczwara B: Collaborating or coexisting: A survey of attitudes of medical oncologists toward specialist palliative care. Palliat Med 2009;23:698707.

15. Malin JL: Bridging the divide: Integrating cancer-directed therapy and palliative care. J Clin Oncol 2004;22:34383440 .

16. Deandrea S, Montanari M, Moja L, et al.: Prevalence of undertreatment in cancer pain. A review of published literature. Ann Oncol 2008;19:1985-1991.

17. Charalambous H, Pallis A, Hasan B, et al.: Attitudes and referral patterns of lung cancer specialists in Europe to Specialized Palliative Care (SPC) and the practice of Early Palliative Care (EPC). BMC Palliat Care 2014;13:59.

18. Johnson C, Girgis A, Paul C, et al.: Australian palliative care providers' perceptions and experiences of the barriers and facilitators to palliative care provision. Support Care Cancer 2011;19:343-351.

19. McDarby M, Carpenter BD: Barriers and facilitators to effective inpatient palliative care consultations: A qualitative analysis of interviews with palliative care and nonpalliative care providers. Am J Hosp Palliat Med 2018; [Epub ahead of print]; DOI: 10.1177/1049909118793635.

20. Johnson CE, Girgis A, Paul CL, et al.: Cancer specialists' palliative care referral practices and perceptions: Results of a national survey. Palliat Med 2008;22:51-57.

21. Cherny NI, Catane R, European Society of Medical Oncology Taskforce on Palliative and Supportive Care: Attitudes of medical oncologists toward palliative care for patients with advanced and incurable cancer: Report on a survery by the European Society of Medical Oncology Taskforce on Palliative and Supportive Care. Cancer 2003;98:2502-2510.

22. Hui D, Elsayem A, De la Cruz M, et al.: Availability and integration of palliative care at US cancer centers. JAMA 2010;303:1054-1061.

23. Donkor A, Luckett T, Aranda S, et al.: Barriers and facilitators to implementation of cancer treatment and palliative care strategies in low- and middle-income countries: Systematic review. Int J Public Health 2018;63:1047-1057.
24. Hancock K, Clayton JM, Parker SM, et al.: Truth-telling in discussing prognosis in advanced life-limiting illnesses: A systematic review. Palliat Med 2007;21:507-517.

25. Baile WF, Lenzi R, Parker PA, et al.: Oncologists' attitudes toward and practices in giving bad news: An exploratory study. J Clin Oncol 2002;20:2189-2196.

26. Laryionava K, Heußner P, Hiddemann W, et al.: 'Rather one more chemo than one less...': Oncologists and oncology nurses' reasons for aggressive treatment of young adults with advanced cancer. Oncologist 2018;23:256-262.

27. Schildmann J, Tan J, Salloch S, et al.: 'Well, I think there is great variation...': A qualitative study of oncologists' experiences and views regarding medical criteria and other factors relevant to treatment decisions in advanced cancer. Oncologist 2013;18:90-96.

28. Broom A, Kirby E, Good P, et al.: The troubles of telling: Managing communication about the end of life. Qual Health Res 2014;24:151-162.

29. Christakis NA: Prognostication and bioethics. Daedalus 1999;128:197-214.

30. Hancock K, Clayton JM, Parker SM, et al.: Discrepant perceptions about end-of-life communication: A systematic review. J Pain Symptom Manage 2007;34:190-200.

31. van Vliet LM, van der Wall E, Plum NM, et al.: Explicit prognostic information and reassurance about nonabandonment when entering palliative breast cancer care: Findings from a scripted video-vignette study. J Clin Oncol 2013;31: 3242-3249.

32. Clayton JM, Hancock K, Parker S, et al.: Sustaining hope when communicating with terminally ill patients and their families: A systematic review. Psychooncology 2008;17: 641-659.

33. Gordon EJ, Daugherty CK: 'Hitting you over the head': Oncologists' disclosure of prognosis to advanced cancer patients. Bioethics 2003;17:142-168.

34. Broom A, Kirby E, Good P: Referral to specialist palliative care. Intern Med J 2012;42:1040-1042.

35. Broom A, Kirby E, Good P, et al.: The art of letting go: Referral to palliative care and its discontents. Soc Sci Med 2013;78:9-16.

36. Mack JW, Smith TJ: Reasons why physicians do not have discussions about poor prognosis, why it matters, and what can be improved. J Clin Oncol 2012;30:2715-2717.

37. Mack JW, Cronin A, Taback N, et al.: End-of-life care discussions among patients with advanced cancer: A cohort study. Ann Intern Med 2012;156:204-210.

38. Fallowfield LJ, Jenkins VA, Beveridge HA: Truth may hurt but deceit hurts more: Communication in palliative care. Palliat Med 2002;16:297-303.

39. Friedman BT, Harwood MK, Shields M: Barriers and enablers to hospice referrals: An expert overview. J Palliat Med 2002;5:73-84.

40. Miyashita M, Hirai K, Morita T, et al.: Barriers to referral to inpatient palliative care units in Japan: A qualitative survey with content analysis. Support Care Cancer 2008; 16:217-222.

41. Morita T, Miyashita M, Tsuneto S, et al.: Late referrals to palliative care units in Japan: Nationwide follow-up survey and effects of palliative care team involvement after the Cancer Control Act. J Pain Symptom Manage 2009;38:191-196.

42. Collins A, McLachlan S-A, Philip J: Initial perceptions of palliative care: An exploratory qualitative study of patients with advanced cancer and their family caregivers. Palliat Med 2017;31:825-832. 
43. Fadul N, Elsayem A, Palmer JL, et al.: Supportive versus palliative care: What's in a name? A survey of medical oncologists and midlevel providers at a comprehensive cancer center. Cancer 2009;115:2013-2021.

44. Dalal S, Palla S, Hui D, et al.: Association between a name change from palliative to supportive care and the timing of patient referrals at a comprehensive cancer center. Oncologist 2011;16:105-111.

45. Rodriguez KL, Barnato AE, Arnold RM: Perceptions and utilization of palliative care services in acute care hospitals. J Palliat Med 2007;10:99-110.

46. Hui D, Mori M, Parsons HA, et al.: The lack of standard definitions in the supportive and palliative oncology literature. J Pain Symptom Manage 2012;43:582-592.

47. Kelley AS, Meier DE: Palliative care-a shifting paradigm. N Engl J Med 2010;363:781-782.

48. Smith TJ, Temin S, Alesi ER, et al.: American Society of Clinical Oncology provisional clinical opinion: The integration of palliative care into standard oncology care. J Clin Oncol 2012;30:880-887.

49. Temel JS, Greer JA, Muzikansky A, et al.: Early palliative care for patients with metastatic non-small-cell lung cancer. N Engl J Med 2010;363:733-742.

50. Temel JS, Greer JA, El-Jawahri A, et al.: Effects of early integrated palliative care in patients with lung and GI cancer: A randomized clinical trial. J Clin Oncol 2017;35: 834-841.

51. Bakitas M, Lyons KD, Hegel MT, et al.: Effects of a palliative care intervention on clinical outcomes in patients with advanced cancer: The project ENABLE II randomized controlled trial. JAMA 2009;302:741-749.

52. Bakitas MA, Tosteson TD, Li Z, et al.: Early versus delayed initiation of concurrent palliative oncology care: patient outcomes in the ENABLE III randomized controlled trial. J Clin Oncol 2015;33:1438-1445.

53. Zimmermann C, Swami N, Krzyzanowska M, et al.: Early palliative care for patients with advanced cancer: A clusterrandomised controlled trial. Lancet 2014;383:1721-1730.

54. McCorkle R, Jeon S, Ercolano E, et al.: An advanced practice nurse coordinated multidisciplinary intervention for patients with late-stage cancer: A cluster randomized trial. J Palliat Med 2015;18:962-969.

55. Maltoni M, Scarpi E, Dall'Agata M, et al.: Systematic versus on-demand early palliative care: Results from a multicentre, randomised clinical trial. Eur J Cancer 2016; 65:61-68.

56. Vanbutsele G, Pardon K, Van Belle S, et al. Effect of early and systematic integration of palliative care in patients with advanced cancer: A randomised controlled trial. Lancet Oncol 2018;19:394-404.

57. Gaertner J, Wolf J, Voltz R: Early palliative care for patients with metastatic cancer. Curr Opin Oncol 2012;24:357-362.

58. Greer JA, Jackson VA, Meier DE, et al.: Early integration of palliative care services with standard oncology care for patients with advanced cancer. CA Cancer J Clin 2013;63:349-363.

59. Back AL, Park ER, Greer JA, et al.: Clinician roles in early integrated palliative care for patients with advanced cancer: A qualitative study. J Palliat Med 2014;17:1244-1248.

60. Agence Nationale d'Accréditation et d'Evaluation en Santé (ANAES): Modalités de prise en charge de l'adulte néce- ssitant des soins palliatifs. Available from https://www .has-sante.fr/portail/upload/docs/application/pdf/txt_soins_ palliatifs_recommendations_final_es_mise_en_ligne.pdf (last accessed December 14, 2018).

61. Société Française d'Accompagnement et de Soins Palliatifs: Annuaire des structures de soins palliatifs et des associations de bénévoles d'accompagnement de la SFAP. 2017. http://sfap.org/rubrique/en-quelques-chiffres (Last accessed July 30, 2018).

62. Charmaz K: Constructing Grounded Theory. 2nd edition. Los Angeles, London, New Delhi, Singapore, Washington, DC: Sage, 2014.

63. Peretti-Watel P, Bendiane MK, Moatti JP: Attitudes toward palliative care, conceptions of euthanasia and opinions about its legalization among French physicians. Soc Sci Med 2005;60:1781-1793.

64. Moulin P: Les soins palliatifs en France: Un mouvement paradoxal de médicalisation du mourir contemporain. Cah Int Sociol 2000;108:125-159.

65. Fainzang S: An Anthropology of Lying: Information in the Doctor-Patient Relationship. Oxford, United Kingdom: Routlege, 2015.

66. El-Jawahri A, Traeger L, Park ER, et al.: Associations among prognostic understanding, quality of life, and mood in patients with advanced cancer. Cancer 2014;120:278285.

67. Smith TJ, Dow LA, Virago E, et al.: Giving honest information to patients with advanced cancer maintains hope. Oncology (Williston Park) 2010;24:521-525.

68. Fenton JJ, Duberstein PR, Kravitz RL, et al. Impact of prognostic discussions on the patient-physician relationship: Prospective cohort study. J Clin Oncol 2018;36: 225-230.

69. Hannon B, Swami N, Pope A, et al.: The oncology palliative care clinic at the Princess Margaret Cancer Centre: An early intervention model for patients with advanced cancer. Support Care Cancer 2015;23:1073-1080.

70. Hoerger M, Perry LM, Gramling R, et al.: Does educating patients about the Early Palliative Care Study increase preferences for outpatient palliative cancer care? Findings from Project EMPOWER. Health Psychol 2017;36:538548.

71. Weiner JS, Cole SA: Three principles to improve clinician communication for advance care planning: Overcoming emotional, cognitive, and skill barriers. J Palliat Med 2004; 7:817-829.

72. Epner DE, Ravi V, Baile WF: When patients and families feel abandoned. Support Care Cancer 2011;19:1713-1717.

73. Goelz T, Wuensch A, Stubenrauch S, et al.: Specific training program improves oncologists' palliative care communication skills in a randomized controlled trial. J Clin Oncol 2011;29:3402-3407.

Address correspondence to: Aline Sarradon-Eck, MD, PhD Aix Marseille University, INSERM, IRD, SESSTIM 27 Boulevard Jean Moulin 13385 Marseille cedex 5 France

E-mail: aline.sarradon@inserm.fr 


\section{Appendix 1. Physicians' Interview Guide}

\section{Oncologists' Interview Guide}

1. Palliative care (PC)

- Physicians' knowledge of the work done by PC teams and coordination with palliative care specialist (PCS): What is your hospital palliative care provision? Do you work - occasionally/regularly — with specialized palliative care services? In your experience, what is the role of PCS?

(Follow-up questions: How do you contact PCSs? What are your expectations about working together? What problems have you encountered when working together? Have you undergone any training or course in palliative care?)

- In your experience, what does good palliative care consist of?

- Current referral practices: when do you think it is appropriate for a patient to be referred to specialist palliative care services? How do you approach referral with your patients? What are the issues involved in referring patients to specialized palliative care?

(Follow-up question: Do you use the term "palliative care" when talking to your patients about referring them to a palliative care unit?)

\section{Poor prognosis}

- Informing patients about poor prognosis: Do you have difficulty in telling patients that their disease is incurable? If so, why? When do you tell them it is incurable?

(Follow-up questions: at the very first consultation? How do you go about it (what communication strategies do you use?) Who do you inform? Should other members of the family be informed?

- What information do you give them (about the survival time, for example)? How do you assess whether patients want to be informed about the prognosis?

- Have you undergone any training in announcing bad news?

- Have you ever delivered futile end-of-life care?

3. Early Palliative Care (EPC)
- Factors perceived as facilitating or barring access to EPC

(Follow-up questions: organizational, institutional, or communicational factors? Does the EPIC clinical trial seem feasible to you? What are your expectations of this trial?)

4. Sociodemographic data: age sex, the year respondents presented their thesis, and details of their career pathway

\section{PCSs' Interview Guide}

1. Local hospital palliative care provision: how is specialized palliative care organized at this hospital?

(Follow-up questions: Health care professionals? Volunteers? A Mobile Palliative Care Team? Dedicated palliative care beds? An inpatient and/or outpatient Palliative Care Unit?)

2. Current referral practices: At this hospital, are people referred rather late or fairly early to specialized palliative care services? If late, why? What are the barriers? When do you think it is appropriate for a patient to be referred to specialist palliative care services?

3. Coordination with oncologists: Perceived difficulties in working together with oncologists. Do any formal and/or informal meetings with oncologists take place at your hospital?

4. EPC

- Factors perceived as facilitating or barring access to EPC

(Follow-up questions: organizational, institutional, or communicational factors)

- Does the EPIC clinical trial seem feasible to you? What are your expectations of this trial?

- What does good palliative care consist of?

5. Sociodemographic data: age, sex, the year respondents presented their thesis, and details of their career pathway 